\title{
5. Understanding the role of relationships in making career choices among Turkish MBA students
}

\author{
Zahide Karakitapoğlu-Aygün and \\ Kadire Zeynep Sayım
}

\section{INTRODUCTION}

Relationships are central to human functioning. They serve as channels for social resources such as informational, emotional and instrumental support. However, the role of these relational influences in career progress is usually de-emphasized in the literature. Rather, work and relatedness have been perceived as two opposite and distinct modalities of human functioning. Accordingly, work is assumed to represent agency, individuality and separateness, whereas relatedness is assumed to imply dependency. Only in recent years has interest in understanding how relationships and careers are intertwined increased (Blustein, 2001; Blustein et al., 1997; Blustein et al., 2004; Flum, 2001; Schultheiss, 2003; Phillips et al., 2001; Schultheiss et al., 2001). This increased interest in relationships in the organizational research is a reflection of a general tendency away from individualistic explanations toward more relational and contextual ones in social sciences.

The recent research examining the interplay between work and relatedness points to the limitations of stereotypical individual autonomy at the workplace and argues that connectedness with others is essential. For example, based on an extensive literature, Baumeister and Leary (1995) concluded that relatedness is a basic need. Similarly, Bellah et al. (1985) illustrated that people find it difficult to imagine a good life as being lived alone. In their critiques of American individualism, Bellah et al. (1985, p. 82) noted. 'For highly individuated Americans, there is something anomalous about the relation between parents and children, for the biologically normal dependence of children on adults is perceived as morally abnormal.' Hence, 
acknowledging the role of connectedness in human growth and development, in this investigation we broaden the current research by studying the influential role of significant relationships in the career domain. Most of the related research efforts in the area have focused exclusively on how relationships and networks are conducive to career mobility and advancement, overlooking the role of relationships in making career choices. There is, therefore, a need for research exploring what types of relationships matter, and how and why they are significant in making career choices. The present study specifically aims to explore the importance and functions of different relationships (mother, father, relatives, work colleagues, mentors etc.) in making career choices among Turkish MBA students.

\section{CULTURE AND RELATIONAL INFLUENCES}

Culture affects how people think and behave. National culture is embedded in everyday behavior. Accordingly, preferences for the role of social influences in making career choices may differ in individualistic and collectivistic settings. For example, in an individualistic environment where dependence on others is viewed in a negative light, one may value making career decisions independently and the involvement of others in this process is not welcomed. However, in a collectivistic environment where individuals are embedded in close networks, involvement of others may be quite valuable. We argue that understanding the influences of significant relationships on making career choices is especially important in Turkey since it has been considered as 'fundamentally collectivistic' in the literature (Hofstede, 1980). Individuals are strongly tied to family and kinship groups in Turkey. One's sources of self and identity basically refer to social and family networks. Social and familial relationships are regulated by social norms. Despite its fundamentally collectivistic nature, there have been some changes in Turkey in recent years toward individualism. Accordingly, individuals living in a rapidly changing society may be exposed to both individualistic and collectivistic value preferences and may adopt a bi-cultural pattern in which both are emphasized' (Freeman and Bordia, 2001, p. 118). Such tendencies were reported in self-definitions and values of urban and educated Turkish youth (Imamoğlu and Karakitapoğlu-Aygün, 1999, 2004; Karakitapoğlu-Aygün and Imamoğlu, 2002; Karakitapoğlu-Aygün, 2004).

Related research also argued that collectivism depends very much on which in-group (family, friends, coworkers etc.) is present (Triandis et al., 1990). For example, Göregenli (1997) found that when spouse, mother, sibling, friend, relatives, neighbor, co-worker, acquaintance and strangers have been presented as reference groups, Turkish people have been found 
to possess less collectivistic tendencies as the target group or person becomes more psychologically distant. Therefore it is important to understand the influences of significant relationships on career choices in Turkey, which is experiencing rapid socioeconomic changes. In line with the abovementioned research, which implies that individuals tend to report greater intimacy and harmony with in-groups including family and kin, the role of mothers, fathers, significant others/partners and relatives is expected to be greater than that of other non-kin groups. Moreover, since family collectivism is the most salient attribute of the Turkish culture, the roles of kin groups (i.e. mothers, fathers and relatives) were expected to be greater than those of other non-kin groups, including colleagues, managers and friends.

The present study further aims to examine the links between individualistic and collectivistic value orientations at the individual level and the influence of relationships in making career choices among Turkish MBA students. In recent years, culture-level constructs of individualism-collectivism (IC) have been criticized as oversimplifying a complex picture, ignoring within-culture variability and assuming an inherent opposition (Oyserman et al., 2002; Triandis et al., 1988). Accordingly, it has been claimed that those seemingly opposite tendencies may exist together in the same individual (idiocentrism and allocentrism at the individual level corresponding to culture-level IC) and same culture (Triandis et al., 1988). With these critiques in mind, we have tried to overcome those limitations in previous research by considering individual-level value orientations of IC. More specifically, we are interested in the questions 'Do individuals with more collectivistic value orientations tend to be influenced more by their relationships and vice versa?' and 'Which kind of relationships (family or friends, junior or senior work colleagues, mentors etc.) are more influential for individuals with a more collectivistic or individualistic orientation?'

These individual-level IC constructs emphasize separateness or uniqueness versus embeddedness in social relationships. Accordingly, a collectivistic person may be expected to value support from others in his/her career decision-making process, especially from family members and relatives. An individualistic person, on the other hand, might not value involvement of others in such an important issue for his/her personal life. However, recent developmental and social psychological research illustrates that these two constructs of IC or autonomy/independencerelatedness are complementary (Flum, 1994; Guisinger and Blatt, 1994; Imamoğlu, 2003). In other words, independence and autonomy may grow with relatedness and vice versa. Then, in the present study, one may expect both individualistic and collectivistic value orientations to have positive effects on the role of relationships in career decision making, with stronger effects for collectivism. 
Furthermore, related research suggests that there is a positive relationship between collectivism and family relatedness; and individualism and peer relatedness (Benet-Martinez and Karakitapoğlu-Aygün, 2003; Kwan et al., 1997). The latter finding was explained by the fact that individualistic orientation leds people to have friends of their own choosing with whom they share interests and values. This research, although scant, implies that collectivistic tendencies are more associated with in-group members such as family, relatives etc., whereas individualistic tendencies seem to be associated with relationships involving friends and colleagues from school and work. Unfortunately, there is not much research investigating the differential role of peers, colleagues, mentors, managers etc. in career decision making. To fill this gap, juniors, peers, senior work colleagues, managers, lecturers, instructors and mentors were also included in the present study. In the light of the above-mentioned research, one may expect collectivism to have positive effects on the influences of family and kin (i.e. mothers, fathers, relatives or significant other) and individualism on the role of peers, work colleagues and managers. Perhaps individuals with a more individualistic orientation make their decisions themselves, signifying that they are the most important agent in making career choices. However, they may consciously and deliberately consult with their colleagues, managers, lecturers and instructors to get more information about their alternatives and to widen their options before making a vital decision for themselves. Then, individuals with more collectivistic orientations may be influenced by the opinions of their family and kin, whereas students with more individualistic orientations may be expected to consult with their peers, colleagues, managers from work, and lecturers and instructors from school.

\section{GENDER AND RELATIONAL INFLUENCES}

Another aim of the present study is to elucidate gender-related differences in the role of significant relationships in making career choices. The issue of gender has special significance in the context of career choice due to a longstanding controversy about the existence of gender difference in management and careers. Researchers differ in their opinions regarding the study of sex differences. For example, Baumeister (1988) advocates the abandonment of sex differences since they are no longer necessary or advisable. On the other hand, Eagly (1987), Rothblum (1988) and Lefkowitz (1994) propose the investigation of sex differences in organizational behavior to explore similarities as well as differences. As Eagly (1987, p. 756) puts it, 'null findings, if obtained consistently across studies, would help establish that 
women and men are similar in many respects'. We agree with these researchers and claim that sex differences or similarities in management and career choice are worth investigating. As Lefkowitz (1994, p. 341) suggests, 'even null findings are important information given the prevalence of gender stereotypes, and because the few robust differences that may be confirmed become even more noteworthy and interesting to explore'.

One line of gender research (e.g. Fisher, 1999) argues for significant differences among sexes in work attitudes, values and behaviors. For example, women have been found to emphasize relatedness and embeddedness with others, opportunity for interaction with people, fair and considerate supervision, social approval and short-term career goals (Elizur, 1994; Lynn, 1993; Sagie et al., 1996). Men, on the other hand, were found to value independence, autonomy, money, competitiveness, rewards and long-term career goals. These differences between men and women appear to support the argument that women's reactions are different from those of men as a result of some biological factors or of differential sex-role socialization (Chodorow, 1978; Fisher, 1999). According to this theorizing, today's gendered division of labor is explained by the differential interests of men and women. Men and women have particular predispositions or are being socialized differently and accepting different gender roles. Therefore their career choices and work behavior reflect their orientations. Women tend to emphasize relatedness with others more than men do, implying stronger effects of relationships on women (Gilligan, 1982; O'Brien, 1996).

The other line of research, however, mostly representing a social perspective, argues for lack of significant gender differences in management and careers. For example, Kanter $(1977,1993)$ argues that our attitudes and behaviors at work are determined by social structures in the workplace, but not personal dispositions. One of her arguments is that one's attitudes toward work and behaviors at the workplace have nothing to do with a person's sex, but with the person's position, job situations, and the tasks $\mathrm{s} / \mathrm{he}$ does at the workplace. Women's weaker tendencies toward careers could then be explained by their being in subordinate positions in the organizations, not by their personality traits. Supporting Kanter's arguments, Lefkowitz (1994) found that gender-related differences in work preferences, values and attitudes were spurious effects of other variables such as job characteristics, age, tenure, income and occupational level. When these factors were controlled, genders tend to be similar in their preferences.

In the current chapter the issue of gender was examined at the beginning of the path towards a career in management among young men and women MBA students. By studying the possible gender effects in the role of relationships in making career choices, the present study tries to increase understanding of the theoretical controversy regarding the gender differences in 
careers and work life. With regard to gender issue in career choice, we adopted a discovery-oriented approach and derived no specific hypotheses. Rather, the aim was exploratory with regard to similarities or differences across genders in the Turkish context.

\section{METHODOLOGY}

The study consists of two parts. In the first, quantitative, part, the influence of relational agents in career choice and the links to individualistic-collectivistic value orientations were investigated as well as gender differences in the relational influences. In the second, qualitative, part, the roles that relationships play in shaping individuals' career choices were studied through in-depth semi-structured interviews.

\section{Quantitative Study}

\section{Participants}

A total of 116 (69 men, 47 women, with a mean age of 23.46) Turkish MBA students participated in the first part of the study. Students were drawn from two large well-known universities, one in Ankara and one in Istanbul. As shown in Table 5.1, almost half of the sample had no work experience and, consequently, mean length of service in current employment was low. In line with their current job condition, most of the students relied on their parents for MBA funding. Almost half of them reported starting their own business or entrepreneurship as their primary career goal, while the rest emphasized being a manager and advancement in their careers as major goals.

\section{Measures and procedure}

The Turkish and UK versions of the scales were checked through back translations. Native speakers of English and Turkish also checked the scales for wording, accuracy and clarity of items in both languages. Questionnaires were group-administered to students in class. The participants were assured that their responses would be anonymous and confidential.

\section{Influences of relationships on career choice scale}

Participants were asked to consider the listed individuals or groups in terms of their influence on their career choice. The relationships listed were: (1) mother; (2) father; (3) relatives; (4) friends; (5) junior work colleagues; (6) peer work colleagues; (7) senior colleagues; (8) senior managers; 
Table 5.1 Sample characteristics (percentages in parentheses)

\begin{tabular}{lc}
\hline Variables & \\
\hline No. of participants & 116 \\
Men & $69(59.5)$ \\
Women & $47(40.5)$ \\
Mean age & 23.46 \\
Mean years of high education & 3.70 \\
Mean years in current employment & 2.04 \\
Occupational status & \\
White-collar & $35(30.2)$ \\
Blue-collar & - \\
Pink-collar & $2(1.7)$ \\
Student & $63(54.3)$ \\
Other & $6(5.2)$ \\
Career goal & \\
Management & $36(31)$ \\
Own business & $41(35.3)$ \\
Entrepreneurship & $5(4.3)$ \\
Career advancement & $26(22.4)$ \\
Career change & - \\
Other & $5(4.3)$ \\
Funding for MBA study & \\
Self & $15(12.5)$ \\
Parents & $76(65.5)$ \\
Work & $5(4.3)$ \\
Self and parents & $12(10.3)$ \\
Self and work & - \\
Other & $8(6.9)$ \\
Current job condition & \\
No work experience & $50(43.1)$ \\
Unemployed & $32(27.6)$ \\
Doing paid work & $32(27.6)$ \\
\hline
\end{tabular}

(9) fellow students; (10) lecturers; (11) mentors; and (12) significant other/partner. The response scale was the 7-point Likert scale, where 1 indicated 'no influence at all' and 7 indicated 'great influence'.

\section{Individualism-collectivism}

Individualistic and collectivistic value orientations were also measured on a Likert scale, where 1 referred to 'strongly disagree' and 7 'strongly agree'. In this scale (Triandis and Gelfand, 1998), individualism was measured by six items, such as 'Winning is everything' and 'I'd rather depend on myself', 
whereas collectivism was measured by nine items, such as 'Parents and children must stay together as much as possible' and 'If a co-worker gets a prize, I feel proud'. Cronbach's alpha values were 0.70 for individualism and 0.64 for collectivism.

\section{The Results of the Quantitative Study}

To explore gender differences in types of relationships, t-tests were conducted. Moreover, in order to explore associations with individualistic and collectivistic value orientations, correlations between IC and relationship types were computed.

\section{The importance of relationship types and gender differences}

As shown in Table 5.2, fathers were rated as having the greatest influence on career choice of Turkish MBA students, followed by lecturers and mothers. Junior and peer work colleagues, on the other hand, were found to be least influential. Contrary to our expectations, relatives were reported to be among the group of agents who had relatively less influence on career choice of MBA students. Fellow students, friends, mentors and senior colleagues/managers were rated as having a moderate influence on career decision making. Moreover, gender-related analyses illustrated that there were no significant differences between genders in terms of the influence of relationship types. Rather, there were very weak trends for relatives, father and

Table 5.2 Gender differences in relationship types

\begin{tabular}{|c|c|c|c|c|c|c|c|}
\hline & \multicolumn{2}{|c|}{ Men } & \multicolumn{2}{|c|}{ Women } & \multicolumn{2}{|c|}{$\begin{array}{l}\text { Entire } \\
\text { sample }\end{array}$} & \multirow[t]{2}{*}{$\mathrm{t}$} \\
\hline & M & $\mathrm{SD}$ & M & $\mathrm{SD}$ & M & $\mathrm{SD}$ & \\
\hline Mother & 3.35 & 1.89 & 3.80 & 1.89 & 3.53 & 1.89 & -1.25 \\
\hline Father & 3.77 & 1.94 & 4.16 & 2.00 & 3.92 & 1.96 & -1.03 \\
\hline Relatives & 2.43 & 1.63 & 2.02 & 1.35 & 2.27 & 1.54 & 1.40 \\
\hline Friends & 3.26 & 1.89 & 2.91 & 1.79 & 3.12 & 1.85 & 0.98 \\
\hline Junior work colleagues & 1.90 & 1.47 & 1.70 & 1.20 & 1.83 & 1.37 & 0.71 \\
\hline Peer work colleagues & 2.03 & 1.63 & 2.05 & 1.56 & 2.04 & 1.60 & -0.07 \\
\hline Senior colleagues & 2.44 & 2.01 & 2.19 & 1.78 & 2.35 & 1.93 & 0.62 \\
\hline Senior managers & 2.61 & 2.11 & 2.79 & 1.86 & 2.68 & 2.02 & -0.44 \\
\hline Fellow students & 3.48 & 1.74 & 3.41 & 1.91 & 3.45 & 1.80 & 0.20 \\
\hline Lecturers & 3.54 & 1.97 & 3.75 & 1.97 & 3.62 & 1.97 & -0.56 \\
\hline Mentors & 2.84 & 2.03 & 3.02 & 2.02 & 2.91 & 2.02 & -0.46 \\
\hline Significant other/partner & 2.70 & 2.03 & 2.93 & 1.87 & 2.79 & 1.97 & -0.62 \\
\hline
\end{tabular}


mothers. Accordingly, women tended to be more influenced by their parents and men by their relatives, in comparison to the other gender.

\section{Correlations between individual-level IC and relationship types}

In terms of the correlations between relationship types and individualistic-collectivistic value orientations, our results revealed that individualism was a more important predictor of being influenced by one's significant relationships in Turkey (see Table 5.3). Interestingly, individualism was positively associated with being influenced by one's junior, peer and senior work colleagues, as well as the senior managers at the workplace. Collectivism, on the other hand, was only associated with the involvement of fathers in the career decision-making process, supporting the patriarchal nature of Turkish society.

\section{Qualitative Study}

In addition to quantitative data, qualitative data were gathered through interviews to deepen our understanding of the role that relationships play in shaping individuals' career decision-making process. To clarify the role of relationships in career choices, in-depth semi-structured interviews were conducted with 13 (8 men, 5 women) Turkish MBA students. Ten had engineering backgrounds, as is usually the case with Turkish MBA students, whilst the other three had social science degrees. Some of the interviewees were drawn from those who had already participated in the quantitative

Table 5.3 Correlations between type of relationships and individualistic-collectivistic values

\begin{tabular}{llc}
\hline & \multicolumn{2}{c}{ Turkey } \\
\cline { 2 - 3 } & \multicolumn{1}{c}{ Ind. } & Col. \\
\hline Father & 0.08 & $\mathbf{0 . 2 3}$ \\
Junior work colleagues & $\mathbf{0 . 2 3} *$ & -0.00 \\
Peer work colleagues & $\mathbf{0 . 2 2 *}$ & 0.04 \\
Senior colleagues & $\mathbf{0 . 3 5}^{* * *}$ & 0.17 \\
Senior managers & $\mathbf{0 . 2 2 *}$ & 0.14 \\
Fellow students & 0.06 & 0.07 \\
Mentors & 0.13 & -0.07 \\
Significant other/partner & 0.12 & 0.06 \\
Total influence of relationships & $\mathbf{0 . 2 0 *}$ & 0.08 \\
\hline
\end{tabular}

$\mathrm{p}<0.05 ; * * \mathrm{p}<0.01 ; * * * \mathrm{p}<0.001$. 
study. In the interviews, we asked them about the agents (e.g. 'We would like to elaborate on the people who have been influential in your career choice. Please rank the three most influential people (or groups of people) in your career choice decision-making process'), types of influences of these relations on the career choice (e.g. 'What kind of influences did this person have on your career choice?'; 'How did this person influence your career choice?') and the reasons of such influence (e.g. 'Why was it your mom/dad/uncle/etc. who had been most influential in your career choice?') to further elaborate the relations and their influences. After the first couple of interviews, it occurred to us that our participants actually made at least two career choices: first when they decided their area of study in their first degrees and second when they decided to do an MBA. Therefore we started to ask the same questions separately for their career choice decisions for their first degrees and then for their MBA degrees. The interviews were conducted in Turkish (the native language of both the interviewees and the interviewer), taped with the consent of the participants and transcribed verbatim. Transcriptions were coded for the agents and the relational dimension categories. Analyses of the transcriptions were done first within cases, and then across cases. The findings revealed, first, the influential agents, and second, the various relational influences they had on the career choices of Turkish MBA students. In the next section, we will discuss these findings within the framework of Schultheiss et al.'s (2001) relational influence dimensions by citing examples from the interviews.

\section{Influential agents and relational dimensions}

Our results showed that the three most influential relational agents reported included parents, close relatives (particularly uncles) and acquaintances (parents' friends and colleagues, distant relatives), high school teachers and university professors, friends, higher-level managers, and older siblings, not necessarily in this order.

Relational influence categories found were classified into those domains suggested by Schultheiss et al. (2001) as role model influences, emotional support, information support, esteem support and social integration. The results also revealed that the influential relations, their ranking and the type of influences can be different in the two different career choice stages, pointing to the importance of the timing of the decision.

\section{Parents}

In the majority of the cases, either both or one of the parents (particularly fathers) had been reported among the most influential people in the interviewees' initial career decision-making process in various relational dimensions. Parents, especially fathers, were first perceived as a positive role model 
when uninformed young students were trying to decide which profession to choose. The following account by Interviewee No. 1 illustrated this relational dimension, where the father acted as an admirable example that the interviewee had looked up to:

My father is a mechanical engineer and so am I. He is a hardworking successful person; as a manager he had a good status in the society and in the smaller communities we lived in. He did not talk too much about the financial aspects of his profession at home, nothing more than what I had been able to observe, but within the family environment you kind of know. In any case, he had earned a decent living and provided a good living standard for our family; he was successful. So I thought I could be like this, I could own similar things. So I guess I saw him as a role model.

Our findings revealed that positive role model influences included those relational experiences where the participant felt the need for the approval and admiration of the influential person, for which Interviewee No. 12's account presented clear evidence:

I am my daddy's girl. For me, he is in such high place. I always take him as an ideal example. It is very important for me that my father is proud of me and that I honor him. He is my idol. Therefore his influence on me, on everything I do, is very great. He usually lets me be but it is very important for me to feel his presence in the background. I need to earn his approval and not disappoint him.

\section{Mothers}

In addition to fathers, mothers were also listed among the first or second most influential people in career choices. However, in only one case had a mother a positive role model influence in the initial career choice. As an engineering graduate from one of the best universities in Turkey, she had a profile of most role model fathers. She had worked at important government organizations and state-owned enterprises. Her prestigious university and continued relations with her university friends influenced Interviewee No. 3 in choosing to do an engineering degree at the same university. Additionally, Interviewee No. 1 took his mother as a positive role model when he wanted to make a career change from engineering and decided to do an MBA.

Mothers as the most influential people in career choice decisions were mostly found to play emotional and/or information support roles either on their own or together with fathers. As our participants' accounts indicated, mothers provided 'relational influences in terms of emotional support, closeness, encouragement and reducing stress and alleviating stress' (Schultheiss et al., 2001, p. 225). Interviewee No. 6, for instance, stated that his mother played a significant emotional support role when she encouraged him to make his own choice during the initial career decision-making 
process. She had defended the idea that the participant could select a different university from his father's preference for him. Interviewee No. 12 listed her mother as the second most influential person in her career decision-making process. This participant's mother played the more traditional Turkish mother role: first, as a mediator between the father and the daughter when the latter took an argumentative stance and wanted to make her own decisions; second, a caring role which signals the traditionally accepted approach towards women's employment or career in Turkey where the mother advised that her daughter should chose a 'woman's' job, which would not require too much hard work and effort. Interviewee No. 12 moreover indicated that:

My mother is like my friend. She gives me advice like a friend. I consult her and she is my advisor. Her importance for me is more emotional. I trust her and believe that I should consider her suggestions seriously.

Some of the participants emphasized the significance of the emotional support dimension of their relations with their both parents in the career decision-making stage. Interviewee No. 10's account is a good example that shows the significance of an emotionally supportive relation with the parents:

My parents have always encouraged me to do whatever I think would make me happy. It was the same when I decided to do an MBA. There were possibilities of going to the UK or to Istanbul. My father for instance suggested that I could go to Istanbul or to the States. But he never forced me to do anything. They always suggested alternatives. Then during the 1st semester I had experienced difficulties in adapting to the program here, basically because of my background in international relations as this is a very quantitative course and majority of the participants have engineering backgrounds. I had thought of leaving the program. My parents said I could leave it or ask for a suspension and then decide whether to go back or not. Such an understanding positive approach had helped a lot. I am influenced by people who have a positive approach. Also people in my life have a priority ranking: my mom, dad, friends, they are all very important for me. These people always showed their support to me.

In addition to emotional support, mothers took information support roles where they acted as a source of career information (Schultheiss et al., 2001). For Interviewee No. 7 his mother was a resource for direct career advice:

I considered studying management among my other choices in the undergraduate level. But my mother told me that I could do an MBA on top of my engineering degree. So she influenced me to choose engineering instead of management. 
Mothers typically offered career assistance by collecting information on specific courses, job opportunities and labor market conditions for their children, even if they were not the direct resource themselves. Interviewee No. 1's mother was reported to be very influential at the time of his career change decision from engineering to management when she pointed that he could get an MBA and provided information collected from her friends and their children studying for their MBAs and showed how they used it to make a career change, to help the participant to make his own career decision.

A distinctive dimension from those identified by Schultheiss et al. (2001) was reported by the Turkish participants in this study of their relations with their parents. It can be described as a combination of two dimensions by Schultheiss et al. (2001), namely, parent(s) acting as a source of conflict, and the importance of their specific personality characteristics (dominant and controlling) or ideas (ideology) held by them. However, in the Turkish context, the nature of the relationship was stronger than defined by Schultesiss et al. (2001) due to other important factors such as submissive attitude by children towards the authority of their parents. This dimension of the relationship to the parent(s), which is quite common in Turkey, we described as 'push influence'. In many ways, this might be considered not as a social 'support' relation, as it usually created pressure on the participants and influenced their career decision-making process negatively. An extreme example of such a relation was illustrated by Interviewee No. 11, who was strongly encouraged by her parents to choose a certain area, i.e. medicine, to study at university. She wanted to do media studies or law but when she could not convince her parents, she had chosen management as a 'proxy', although she did not know what management was exactly about. She thought it was a more prestigious field of study than media and was closer to her areas of interest than medicine. So she had chosen her profession after high school as a reaction to the pressure exerted upon her by her parents. This 'push influence' relation to her parents continued after her first degree, when they insisted that she should do an MBA. What her parents really hoped was that she would continue with an academic career, following their footsteps as well as other close relatives such as her uncle, 'at least in management'. The pressure exerted upon Interviewee No. 11 had resulted in a completely different career path for her, as she could not persuade her parents to let her make her own choice.

A similar account of 'push influence' was told by Interviewee No. 7, whose experience had not resulted in such a dramatic outcome:

Both my parents wanted me to study medicine very much. I did not want it at all but I thought I could be helpful to my family, had I become a doctor. My 
grandmother, my aunts, they all wanted me to go to medical school. I believed that it is a very prestigious profession as well. So I put it among my choices in the university placement exam. If I had been placed in the medical school, I would have studied there. My parents and relatives directly influenced me in my choice; and actually I could have ended up in the medical school.

This evidently common dimension among Turkish parents in their relations to their children at career decision-making stages was sometimes strongly resisted, as was told us by Interviewee No. 13. His father pushed him towards a more traditional choice of career, i.e. studying medicine to become a doctor:

You know, in the east [of Turkey] families want their children to study medicine. My father told me that I should definitely study medicine, as there is not any doctor in our family. But this pushy approach backfired on me and I resisted choosing to study medicine. I felt like he was forcing me and I insisted in my own decision.

\section{Relatives and acquaintances}

In addition to parents, trusted close relatives (particularly uncles) and more distant relatives and acquaintances (parents' friends and colleagues, neighbours, etc.) were reported among the most important relations in the career decision-making process. Their relations to the participants were influential in essentially two ways, first as a positive role model, and second as providers of information support. For Interviewee No. 3, his uncle had been very strongly influential as a positive role model, indicated in the following vignette:

My uncle had gone to Istanbul and studied and worked at the same time, earning his living. He has got such an incredible life now. He provides excellent education opportunities for his children. His current status in life is wonderful. When I considered his position, I thought to myself that I could be like that too. I don't know, somehow such strong characters influence me. I always think that they do the best and if I follow their footsteps I would do the best as well.

This uncle's experiences and accomplishments had influenced the participant so much that he had become the role model whom the participant aspired to resemble and made his career decision accordingly. Similarly, Interviewee No. 13's uncle was the most influential relation as a positive role model while making his career choice so that he followed his uncle's path:

My uncle studied and graduated from one of the best universities of Turkey. I come from Diyarbakir [one of the least developed towns, in the south-east of Turkey] and he was the first in our family who went to a big city and attended 
this particular university. He was the most popularly accepted person in my family. He had that very good image. He had this significant place in the family and his ideas were extremely valued by family members. He received an exceptional respect from all of us. He had painted me a picture where I should go to the same university. So I was attracted to the idea of going to this school.

For Interviewee No. 4, his uncle's success and respected position in the family were important factors that made the participant to look up to him. He had also held an information support role, partly as a consequence of his admired position:

$\mathrm{He}$ is a very successful person in our family and someone I always trusted. $\mathrm{He}$ did not apply any pressure on me but he said that if he was going to make a choice now, he would have studied industrial engineering. He had also described the environment at his university as very attractive and told me that I would enjoy my four years of higher education period there. He also convinced me that I shall be able to find good job prospects after graduation and I could be promoted easily as a graduate of this particular school.

Many participants indicated that they had benefited from information support by distant relatives and acquaintances during their career decisionmaking process. The following account by Interviewee No. 13 can be given as a representative example of such an information support relation between the participant and various acquaintances:

Most Turkish students make uninformed choices at the time of the university placement exam. We don't know much about the professions, course contents, what kind of difficulties the courses or later the profession involve. These acquaintances who were in the academia provided me with such kind of information. They asked me about my interests and capabilities. They told me for instance engineering courses involve a great deal of mathematics and asked me whether I like maths that much or whether I feel I could be successful at it. They have experience and knowledge in career choice, they come across many different cases. Therefore I trust them.

One dimension that did not come up strongly in the accounts by the participants about their relations with parents was esteem support. It was, however, indicated in their relations with other relatives as well as school teachers and university professors. This dimension is described by Schultheiss et al. (2001, p. 226) as 'feeling pushed to perform up to one's potential, feeling another's confidence in their abilities, experiencing freedom regarding exploration and decision making, being encouraged to be responsible for one's decisions, and learning from one's mistakes'. The following account by Interviewee No. 3, for instance, demonstrates that she 
felt positively pushed by her close relatives to perform up to her fullest potential:

I guess I have this image in the family as 'She can do this. She is good. She works hard.' They say, 'you like to study, you are apt to studying hard. You are an ambitious person, so you have to accomplish these at your age now.'

\section{School teachers and university professors}

School teachers and university professors were reported among the most influential people in the career decision-making process. Some of our participants indicated an esteem support relation with their high school teachers that had made them feel the latter's trust in their capability and potential, as evident in the following vignette by Interviewee No. 13:

My high school teachers had steered me towards this university and engineering. This was basically because of the prestigious image of this university: no one from my high school had studied at this very well-known Turkish university before and they thought I could do it. They always told me that I was the one who could achieve such a success. And I would be very successful in the work life one day. And I really like to be praised, I am positively influenced by being praised. I am motivated when I know that people think about me as such.

Others were influenced by their professors' (especially in the MBA program) encouragement to perform up to their potential, as was mentioned by Interviewee No. 3:

Some professors here at the MBA program had mentioned that I should have taken the top scores in the exams and asked me why I did not. I was motivated thinking that they had such an expectation from me, so I could do better.

For some participants, their relation with their university professors (at the undergraduate or postgraduate level) was a combination of positive role model and information support. Interviewee No. 2, for example, said that the positive, open environment at the department and opportunity for friendly conversations with the professors, their positive attitude towards students, knowledge and expertise in their fields and the examples they brought to the class had been very influential in his decision about how to continue his career after finishing the MBA. Interviewee No. 8 was also deeply influenced by the knowledge and experience of some of her instructors in the MBA program and decided to pursue her career in one specific branch of management. She felt that "my career had found a path after I started this MBA programme. Previously it was all coincidence but now I think I am following a certain career path.' 
Quite a few other participants indicated that the information support relation with their university professors was most important, as evident in the following quotation by Interviewee No. 6:

I talked to my professors at my [engineering] department and here at the management department and decided to go for an MBA to be able to make a career change, from engineering to management.

\section{Friends and co-workers}

Another influential agent in career decision-making process cited by the participants was their friends. Particularly at the initial career choice stage, relations with friends had a significant social integration dimension, which refers to 'having someone to talk things over with, sharing similar personality characteristics and interests, and sharing experiences (i.e. comfort and validation in universal experiences)' (Schultheiss et al., 2001, p. 225). This dimension was clearly illustrated by Interviewee No. 6 in the following:

We had talked a lot among friends at school and the preparatory courses before the university placement exam. It was a very difficult period as many things were unknown to us. Perhaps we might have influenced each other with my close friends, as we all chose similar fields. This influence was not like 'let's go to same university or department' and we ended up in various universities and departments. But it was more like talking things over and exchanging information.

Similar aspects of Interviewee No. 9's relation with his high school friends were emphasized in his account:

When we were all preparing for the university placement exam, we discussed among ourselves what we should do. For instance, because we were all good in maths, we decided that our future professions should be in an engineering field. As female candidates, we did not prefer civil or mechanical engineering because of possible work environments. We thought computer engineering would suit us better. We were the same age, we had a similar thought process.

Relations with friends and co-workers at the same level were reported to have role model influences as well, particularly at the time of career change (from engineering to management by doing an MBA) decisions. Interviewee No. 4, for example, had made his decision to do an MBA primarily by looking at the examples of his working friends:

I did not hear any encouraging, exciting information from my friends who had started working right after graduation: work was not exciting, they were not given much discretion or opportunities for creativity or initiative. Another older 
friend had told me about the difficulties of combining work as an engineer in the production and married life with children. To have more alternatives such as working in the finance area, I decided to get an MBA.

The above account in fact was an example of a negative role influence, where the participant decided to do something not to be like the role models. There were positive role model influences as well, such as in the following account by Interviewee No. 8, who had decided to get an MBA degree by looking at the positive examples:

I had in fact always thought of doing an MBA. When I first graduated I actually collected information about MBA programme at this university. But then I started working and attended another masters programme in engineering, and but not an MBA. Then at this workplace, my co-workers were pursuing MBAs so I took example of them.

\section{Higher-level managers}

The other group of influential agents in career decision reportedly included higher-level managers at the workplaces. In addition to parents and close relatives, these people had also evidently been influential as someone the participants admired deeply for their current status and wealth, and took as their 'hero'. These relations had sometimes worked as career counselors, by giving advice on how to proceed with their careers in certain sectors. For Interviewee No. 2, for instance, one top-level manager at his workplace had been extremely influential in deciding to do an MBA to change his career, as explained in the following excerpt from the interview:

This person is also a family friend and he had been very supportive and influential in my career development. He has now a substantial amount of wealth and status as the partner of an American law company while he used to work in a garage 10 years ago. He is self-made man, who had worked while studying. He is fluent in English, you know, which is very important to work in a multinational company. He had suggested that I should do an MBA and I should go to [the name of the university]. He had shown me the way, he is the one who had opened me the doors. I am financially and emotionally indebted to him. If he was not in my life, I would not be sitting in front of you today.

Similarly, Interviewee No. 9 had decided to follow a managerial career by following the example of one top-level manager at his workplace:

When I worked at an IT company as a trainee, the general manager told me that he had an electronic engineering degree and then got an MBA from this school and now he has become the general manager. So I thought to myself I could walk the same road. 
One final illustration of higher-level managers as the most influential 'relations' in career decisions comes from Interviewee No. 11, who had decided to do an MBA, first, by following the example of good role models in the profession, and second, by complying with her current organization's promotion policies and better career prospects:

All the managers in this multinational bank have at least one masters degree. My managers told me that they would consider my career planning after I get my masters degree. So I started this program to extend my career alternatives, in the banking sector or another sector. Moreover I met visionary, really smart and very social high-level managers. They impressed me a lot about choosing banking in the first place. I am not yet completely sure about pursuing a career in banking but these top-level managers I met in this organization had influenced me by their status in the society.

\section{Success stories}

We have two interesting findings in the qualitative part of this study. First, even if they cannot really be considered as 'relations', some well-known entrepreneurs and business people had an influence on some of the interviewees in their career decision making by having success stories to tell. The following quotation by Interviewee No. 2 demonstrates such an influence:

Large companies' bosses that I follow from the media or Internet have been very influential on my decision in doing an MBA. I read the life stories of big names, such as Bill Gates or Ted Turner. I am influenced by these people's successes, not by the success of the corner store owner, you know. And I want to be like them.

Interviewee No. 6, as an ambitious person at the beginning of his career, explained why he had been positively influenced by the success stories of such people:

I read success stories of well-known international entrepreneurs, such as how Henry Ford made it or the person who had established Xerox made it. Their independent minds, earning a lot of money and different way of looking at things, had all influenced me.

Such a 'relation' that can be influential in career decision making was not considered by us when developing the questionnaire; therefore it was not listed among the relationship types to be ranked by the participants according to the significance of their influence. It was, however, mentioned by a few interviewees when talking about the career decision-making process and how they took note of such stories. Therefore this may be an important relation to be considered in future research. 


\section{'Myself'}

The second interesting finding was also about a 'relation' that was not considered by us among the most significant people in career decision making. A number of participants listed 'themselves' explicitly among the three most influential persons in making their career choices. As a very confident and ambitious person, Interviewee No. 2 told us the following:

I was not influenced too much by any one, except by this high-level manager who had been very important by showing me the direction. I have been involved in acting for a long time and it is not very common to change from acting to business. But it all happened entirely by my own decision. When I came here for the [MBA] interview, I could not speak almost any English, my exam scores were not high, I did not even have an GMAT score. But I sat in front of the panel and said 'I am going to do this. I have to do this. I will do this and I am going to do it well.' So they took me in. I rank 'myself' in the first place as I think everyone should rank himself/herself as the most significant person to do something like an MBA. At the end of the day, if you don't want to do something, you don't do it, no one can influence you to.

Interviewee No. 6 also ranked himself among the most influential people in both his initial career choice and later for his career development decision. The following demonstrates how he had used his own discretion in choosing his future careers:

At the time of my initial career choice I had followed the developments in the IT sector closely from the Internet. I was interested in computing and collected information about this field. So I made my own decision. After I graduated as an electronic engineer, I went to the States, and worked and studied at the same time. At that time, I realized that I did not want to do an academic career because it was not the right career path that would take me to the point that I wanted to reach. It was during that time, while reading on marketing for instance that realized I had a very technical approach to issues. I searched about how I could develop my career and that was how I decided that I needed to do an MBA. So I decided on my own to go for an MBA. I told my parents after I made my decision and they did not have any influence. They just asked whether I had considered it thoroughly.

These participants were concerned about taking control of their careers themselves, although they asked for information or were given advice by some relations. Interviewee No. 9 explained how he had decided about his career himself, while he was also influenced by his friends and some relatives and acquaintances:

I felt that I had to make a change because I was afraid that my life would continue like this, writing codes in front of a computer. In order to extend my career alternatives while using my engineering background I decided to do an MBA. 
My parents and some acquaintances suggested that I should work for some time first and then decide. They were concerned that my engineering education would have been wasted. But I made my mind to do an MBA. So it was my own decision and taking initiative. My family members do not understand me, they do not know much about engineering or management. They have a different perspective of career and jobs.

Interviewee No. 13's account about how and why he ranked himself as the third most influential person in making his career decisions clearly shows some common personality characteristic of the participants:

At the end of the day, I made my own decision. I don't like to make my decisions according to other's thoughts. Plus I like to be different from the crowd and be the best in my area. I had thought about going abroad, be different and accomplish big successes. Therefore my own decision making was most important. OK, it was my uncle who told me about this university and get me thinking about studying there. Hence I ranked him as the most influential person in my initial career decision making. But I would not have studied there, had I not decided to. For instance, if I had wanted to study medicine, I would have accomplished that as well.

The above quotations taken from the interview transcriptions showed how the participants explicitly claimed their own significance in career decision making. One last participant, Interviewee No. 5, did not so overtly made a point by listing herself as one of the most influential people in this process. But it was understood from her interview that she had made her own decisions both at the initial and later career choice stages without being influenced too much by any of her social relations. Information support and some emotional support had been all that she had taken from 'others', excluding her parents and other close relatives.

In sum, from this qualitative study it is evident that a number of agents play various relational roles in the career decision-making process. In terms of agents and relational dimensions involved, decision making in career choice is argued to be a multidimensional and multi-level complicated process. Table 5.4 summarizes the findings of our qualitative research in terms of these agents and the relational dimensions of their influence.

\section{DISCUSSION}

In this study, we explored the relatively uninvestigated domain of relational influences on the career choice of MBA students. We have a number of significant findings reached by using a combined qualitative and quantitative research approach. In this section we discuss these findings within the research framework presented earlier. 
Table 5.4 Influential agents and relational dimensions in career decisionmaking process

\begin{tabular}{|c|c|c|c|c|c|}
\hline & $\begin{array}{l}\text { Role model } \\
\text { influence }\end{array}$ & $\begin{array}{c}\text { Emotional } \\
\text { support }\end{array}$ & $\begin{array}{l}\text { Information } \\
\text { support }\end{array}$ & $\begin{array}{l}\text { Esteem } \\
\text { support }\end{array}$ & $\begin{array}{c}\text { Social } \\
\text { integration }\end{array}$ \\
\hline Fathers & + & + & + & & \\
\hline Mothers & & + & + & & \\
\hline $\begin{array}{l}\text { Relatives and } \\
\text { acquaintances }\end{array}$ & + & & + & + & \\
\hline $\begin{array}{l}\text { School teachers } \\
\text { and university } \\
\text { professors }\end{array}$ & & & + & + & \\
\hline $\begin{array}{l}\text { Friends and } \\
\text { colleagues }\end{array}$ & & & & & + \\
\hline $\begin{array}{c}\text { Higher-level } \\
\text { managers }\end{array}$ & + & & & & \\
\hline
\end{tabular}

\section{Emerging Themes in the Interviews}

One interesting theme emerging in the interviews was the timing of the career decision. In other words, the respondents made a distinction between their initial career choices at the undergraduate level and later career choices at the graduate level. The results suggested differences in the importance and functions/roles of relationship types depending on the timing of the career decision. Accordingly, fathers (parents), relatives and teachers acted as influential agents for the initial career decisions. In terms of the roles/functions of these relationship types, the results revealed that these people provided information and emotional support, acted as positive role models, and played more directive and leading roles for the early career choices.

For the later career choices at the graduate level regarding pursuing an MBA degree, the respondents usually referred to individualistic and independent decision making and appeared as confident, ambitious and hardworking students with high aspirations. Having finished their undergraduate studies, they realized that they did not actually want to work as engineers in these particular areas. So they consciously made a decision to change career or widen their options. However, this finding does not necessarily deny the importance of others in career decision making. Rather than solely relying on the influence of others in various relational dimensions, MBA students asked for specific suggestions and direction while making important decisions. Possibly in this way they enhanced their feelings of self-efficacy (Lent et al., 1994). 
At this later career choice stage, the types of relational agents were more or less similar to those reported for initial choices, with the addition of university professors, acquaintances, co-workers and higher-level managers. However, there were differences in the roles/functions of those relationship types. In these later career choices, the influence of those agents took on more of a supportive role as opposed to the directive and leading role in the initial career choices. Those information sources helped MBA students understand their options and, consequently, make a more informed choice. Self-driven, ambitious, more experienced and educated individuals made more conscious decisions, reporting them selves as the most important influential agent in making the career (change) decision. Interestingly, people at the graduate level were influenced by famous success stories of well-known entrepreneurs. That is, they decided to pursue more ambitious careers 'by being different from the crowd' and by using their abilities and potential to improve themselves further through their MBA.

These results suggest that career choice is a complex phenomenon. The type (leading or supportive) and the extent of influence exerted by others differ depending on the time of the decision (i.e. initial and later career path choices) and type of relationship. Individualistic decision making can be more valid in later career choices for particular people (i.e. highly educated, ambitious, self-driven people with probably a more individualistic value orientation). Individualistic decision making does not necessarily mean exclusion of others in career choice. Rather, it seems to include asking for the opinions of trusted people, where the ultimate decision was made independently.

Another important theme that emerged in the participants' reports of most influential people in their career choice was trust, which encapsulated two elements. The interviewees trusted those people who presumably knew them well (i.e. parents, close relatives, friends and teachers). Second, they trusted those they deemed to have expert knowledge of career opportunities, the labor market and advantageous entry routes to these through the education system. Trusted people acted as most influential regarding in particular the initial career choices, i.e. undergraduate degrees.

Consistent with previous research, our findings also confirm the importance of social support (Blustein, 2001; Lent et al., 1994; Phillips et al., 2001; Schultheiss et al., 2001; Schultheiss et al., 2002) and role modeling (Schultheiss et al., 2001) in career choice. The nature of support that emerged in the interviews, such as emotional, informational and esteem support, is consistent with the theoretical functions of support in well-being. In other words, the role of support reported in this investigation is related to enhancing one's ability to deal effectively with stressful situations such as those encountered in career decision making. The present study also contributes to 
the literature on conceptualizations of work by expanding the understanding of how individuals learn about and prepare for their careers. The results suggest that MBA students learn about the world of work from the important people surrounding them. They turn to those people for advice and support. Consequently, those relational agents act as role models, and sources of support and career information for the MBA students.

Not many students reported a 'push influence', especially by their parents who created some pressure on the participants, which negatively influenced their career decision-making process. This finding suggested that incompatible values and expectations of parents and their children may result in conflict, stress, resistance and negative experiences about the involvement of parents. However, the number of respondents who reported such negative experiences was quite small and the majority in general seemed to feel supported and assisted.

\section{Influential Agents and Relational Dimensions}

In terms of who these influential agents are, the results of the quantitative and qualitative studies revealed mostly parallel conclusions. One such result was that parents were rated as having the greatest influence on career choice of Turkish MBA students. This finding is in line with other research, which emphasizes the role of family influence and parental acceptance in collectivistic settings (Leong, 1991; Singarevelu et al., 2005). For example, Tang et al. (1999) illustrate that parental acceptance, not personal interest, determines Asian Americans' career choices. Among the family members, parents, particularly fathers, seem to play the most important role in the career choice of Turkish MBA students. This finding is also consistent with other research from collectivistic contexts where decision making is influenced by family values expressed mostly by the father (McWhirter et al., 1998; Singarevelu et al., 2005). It can also be explained by the paternalistic features of Turkish culture where support, care and protection characterize the relationships (Aycan, 2001). In such a context, the involvement of fathers in career decision making of their children is not surprising. The results of the qualitative study support these conclusions by illustrating that fathers emerge as the sources of information and emotional support for their children. They were also taken as role models, influencing the participants by their status, high-level positions and financial conditions. Although parents were by far the most often cited influential relations, mothers were rarely regarded as role models; their influence was usually limited to emotional and information support.

Another parallel finding of the quantitative and qualitative studies was the influence of school teachers and university professors in the career 
choice of Turkish MBA students. The qualitative investigation revealed that they had evidently influenced the participants by their knowledge of and experience in specific areas to choose certain fields and universities. The significance of the information support dimension of the relation with these agents was primarily due to poorly informed students at their initial career choice stage. As there is no careers advice service in Turkey, high school instructors acted as such, but within their very limited knowledge of both the students and education routes that lead to career opportunities. Suggestions were made mostly according to the most popular, that is prestigious, areas of study and students' levels of attainment. Such positive encouragement and reinforcement of students' potential could increase students' career aspirations and outcomes.

One dissimilar finding across two studies was related to the influences of relatives in career choice. The quantitative study indicated that relatives were rated as having the least influence on career choice of Turkish MBA students, which was surprising given the family-oriented collectivism in Turkey. Yet the results of our qualitative study revealed that well-trusted relatives and acquaintances who achieved a successful career would emerge as sources of expert knowledge about career opportunities and act as role models, having been the first and/or most successful person in the family, especially uncles as sources of expertise and knowledge drawing on their field (i.e. engineering). These inconsistent findings across the two studies emphasize the importance of using both qualitative and quantitative methods in career choice research in order to better delineate the roles and functions of relationships in career decision making.

\section{Gender Differences in Relational Influences}

Regarding gender differences in the influence of relationships in making career choices, no significant effects were observed for any of the relationship types. This interesting finding is supportive of the social perspective in the literature, which argues for the lack of significant gender differences in management and careers (Erez et al., 1989; Kanter, 1977, 1993; Lefkowitz, 1994). Accordingly, our women and men respondents reported similar relational influences, which challenges women's relationality (Chodorow, 1978; Gilligan, 1982). Therefore one can conclude that the extent of gender differences in work values and attitudes tends to decrease as more and more women become a part of the individualistic work realm. One should also keep in mind that our sample consisted of MBA students who came from upper socioeconomic backgrounds. With increased educational attainment and socioeconomic status, Turkish women are becoming more independent and autonomous in terms of values and self-definitions (Imamoğlu 
and Karakitapoğlu-Aygün, 2004; Karakitapoğlu-Aygün, 2004) and more successful in their careers (Aycan, 2004). Therefore, among such an educated and career-oriented group, gender is less likely to play a significant role in the career decision-making process. The lack of gender differences is also supportive of the idea that in a sociocultural environment where establishing and maintaining relationships with others is a main concern, as in Turkey, women and men may equally conceptualize themselves in relational terms (Karakitapoğlu-Aygün, 2004).

\section{IC and Relationship Types}

Finally, IC-related analyses revealed that collectivism was not as important as expected in predicting the influence of significant others in career decision making. As mentioned before, literature on career development emphasizes the influence of collectivist values on career choice behaviors (Leong, 1991; Schultheiss, 2003; Tang et al., 1999). Accordingly, collectivism was associated with strong influence and guidance from others regarding career choice. In the current quantitative investigation that link was only present for fathers, but not for any of the other significant relationship types. This positive association between collectivism and involvement of fathers in career decision making may be perceived as a consequence of the paternalistic characteristics of Turkish culture. However, the lack of significant correlations between collectivism and the influence of other relationship types, especially the other kin members, including mothers and relatives, is interesting. One explanation for this finding may be the changing nature of values in Turkey (Imamoğlu and KarakitapoğluAygün, 1999, 2004). As mentioned before, Turkey has been undergoing a rapid change towards more individualism in recent years. This changing pattern of values was possibly reflected in the career choices of MBA students. In such times of transition, 'fulfilling one's own desires and expectations has become as important as (if not more than) fulfilling other's wishes and expectations' (Aycan and Fikret-Paşa, 2003, p. 139). The lack of significant associations between collectivism and the influence of significant others can also be explained by small sample size and the nature of quantitative investigation. Future qualitative research is needed to further elaborate on the differences among relationship types of MBA students who have individualistic or collectivistic value orientations.

The second IC-related finding was that individualism was positively associated with being influenced by one's junior, peer and senior colleagues, and managers. This finding was in line with our expectations. As mentioned before, students with a more individualistic orientation may rate themselves as the most important agents in their career decisions. They may also be 
more proactive in gathering occupational information, experiences, advice and opinions to increase confidence in their ability to make their own decisions. As they emphasize self-development and personal choice, they may be trying to maximize the benefits of their social networks. As will be recalled, one of the aims of the quantitative study was to answer the question 'Which kind of relationships are more influential for individuals with a more collectivistic or individualistic orientation?' The answer to this question on the basis of our quantitative study would be that fathers seem to be more influential for people with a collectivistic orientation, whereas colleagues from work are more so for people with an individualistic orientation. However, the answer to this question should be further studied through qualitative studies, as our interview results suggested that the majority of our respondents reported some kind of influence from their parents although they were independent decision makers.

\section{Implications}

Although the present study investigated one culture, used a homogeneous sample and collected qualitative and quantitative data with a limited number of respondents, the results have some implications for career theory and practice. Traditional Western career choice theories emphasized independent thought and judgment in career choice. Accordingly, consulting with others has been conceptualized as an obstacle to successful career decisions. Our findings, however, provided general support for the valuable use of others in career decision making. By delineating the link between individual-level IC orientations and the influence of relationships in career choice, the present study also shed light on the differential role of relationships for individuals with different value orientations. In short, the results of the present investigation suggest that while considering career choice, sociocultural factors should be taken into consideration. In a fundamentally collectivistic context, getting relational support may provide an informative view of the real-life context, as well as the ability to cope with the ambiguities associated with career decision making. In such an environment, relational support may not imply conformity, dependency or anomaly (Bellah et al., 1985), but rather a healthy functioning. Therefore career choice seems to be a more complex and intricate issue that should be studied from multiple perspectives (e.g. individual, relational, sociocultural) than most conceptualizations of career choice literature suggest.

Our findings also have some implications for career choice counselors. First, it might be important for counselors to consider how and to what extent their clients are influenced by their particular relationships in career decision making. Second, and perhaps more important, our study has a 
cultural approach. Counselors can make use of our findings while dealing with clients from various ethnic and cultural backgrounds. They can moreover consider individual-level value orientations of clients in terms of IC, and the implications of such value orientations on types and functions of significant relationships. In our study, for instance, although decision makers were independent and active in their career choice, they nevertheless appreciated support and help from significant others. Therefore counselors may pay attention to the fact that significant relationships and their involvement may be quite valuable in the decision-making process of their clients. Finally, it should be noted that since there are no professional career advice services in Turkey, parents, relatives and instructors seem to act as such. The role of the relationships might have been found to be different if such professional services had been in place. More professional advice services would result in better-informed decision making in career choice.

\section{REFERENCES}

Aycan, Z. (2001), 'Human resource management in Turkey: current issues and future challenges', International Journal of Manpower, 22(3): 252-60.

Aycan, Z. (2004), 'Key success factors for women in management in Turkey', Applied Psychology: An International Review, 53(3): 453-77.

Aycan, Z. and Fikret-Paşa, S. (2003), 'Career choices, job selection criteria, and leadership preferences in a transitional nation: the case of Turkey', Journal of Career Development, 30(2): 129-44.

Baumeister, R.F. (1988), 'Should we stop studying sex differences altogether?', American Psychologist, 43: 1092-5.

Baumeister, R.F. and Leary, M.R. (1995), 'The need to belong: desire for interpersonal attachments as a fundamental human motivation', Psychological Bulletin, 117(3): 497-529.

Bellah, R.N., Madsen, R., Sullivan, W.M., Swidler, A. and Tipton, S.M. (1985), Habits of the Heart: Individualism and Commitment in American Life, New York: Harper \& Row.

Benet-Martinez, V. and Karakitapoğlu-Aygün, Z. (2003), 'The interplay of cultural syndromes, and personality in predicting life-satisfaction: comparing Asian- and European-Americans', Journal of Cross-Cultural Psychology, 34: 38-60.

Blustein, D.L. (2001), 'The interface of work and relationships: critical knowledge for 21st century psychology', The Counseling Psychologist, 29: 179-92.

Blustein, D.L., Phillips, S.D., Jobin-Davis, K., Finkelberg, S.L. and Roarke, A.E. (1997), 'A theory-building investigation of the school-to-work transition', The Counseling Psychologist, 25: 364402.

Blustein, D.L., Schultheiss, D.E.P. and Flum, H. (2004), 'Toward a relational perspective of the psychology of careers and working: a social constructionist analysis', Journal of Vocational Behavior, 64: 423-40.

Chodorow, N. (1978), The Reproduction of Mothering: Psychoanalysis and the Sociology of Gender, Berkeley, CA: University of California Press. 
Eagly, A.H. (1987), 'Reporting sex differences', American Psychologist, 42: 756-7.

Elizur, D. (1994), 'Gender and work values: a comparative analysis', Journal of Social Psychology, 134: 201-12.

Erez, M., Borochov, O. and Mannheim, B. (1989), 'Work values of youth: effects of sex or sex role typing?', Journal of Vocational Behavior, 34: 350-66.

Fisher, H. (1999), The First Sex: The Natural Talents of Women and How They are Changing the World, New York: Random House.

Flum, H. (1994), 'The evolutive style of identity formation', Journal of Youth and Adolescence, 23: 489-98.

Flum, H. (2001), 'Relational dimensions in career development', Journal of Vocational Behavior, 59: 1-16.

Freeman, M.A. and Bordia, P. (2001), 'Assessing alternative models of individualism and collectivism: a confirmatory factor analysis', European Journal of Personality, 15: 105-21.

Gilligan, C. (1982), In a Different Voice: Psychological Theory and Women's Development, Cambridge, MA: Harvard University Press.

Göregenli, M. (1997), 'Individualist and collectivist tendencies in a Turkish sample', Journal of Cross-Cultural Psychology, 28: 787-93.

Guisinger, S. and Blatt, S.J. (1994), 'Individuality and relatedness: evolution of a fundamental dialectic', American Psychologist, 49: 104-11.

Hansen, J.I. (1988), 'Changing interests of women: myth or reality?', Applied Psychology: An International Review, 37: 133-50.

Hofstede, G. (1980), Culture's Consequences: International Differences in Workrelated Values, Beverly Hills, CA: Sage.

Imamoğlu, E.O. (2003), 'Individuation and relatedness: not opposing but distinct and complementary', Genetic, Social and General Psychology Monographs, 129(4): $367-402$.

Imamoğlu, E.O. and Karakitapoğlu-Aygün, Z. (1999), '1970lerden 1990lara değerler: Universite düzeyinde zaman, kuşak ve cinsiyet farklılıkları' ('Value preferences from the 1970s to the 1990s: cohort, generation and gender differences at a Turkish university'), Türk Psikoloji Dergisi (Turkish Journal of Psychology), 14(44): 1-22.

Imamoğlu, E.O. and Karakitapoğlu-Aygün, Z. (2004), 'Self-construals and values across different cultural and socio-economic contexts', Genetic, General and Social Psychology Monographs, 130(4): 277-306.

Kanter, R.M. (1977), Men and Women of the Corporation, New York: Business Books.

Kanter, R.M. (1993), Men and Women of the Corporation, New York: Business Books.

Karakitapoğlu-Aygün, Z. (2004), 'Self, identity, and emotional well-being among Turkish university students', Journal of Psychology, 138: 457-78.

Karakitapoğlu-Aygün, Z. and Imamoğlu, E.O. (2002), 'Value domains of Turkish adults and university students', Journal of Social Psychology, 142: 333-51.

Kwan, V.S.Y., Bond, M.H. and Singelis, T.M. (1997), 'Pan-cultural explanations for life-satisfaction: adding relationship harmony to self-esteem', Journal of Personality and Social Psychology, 73: 1038-51.

Lefkowitz, J. (1994), 'Sex-related differences in job attitudes and dispositional variables: now you see them, . ..., Academy of Management Journal, 37(2): 323-49.

Lent, R.W., Brown, S.D. and Hackett, G. (1994), 'Toward a unifying social cognitive theory of career and academic interest, choice and performance', Journal of Vocational Behavior, 45: 79-122. 
Leong, F.T.L. (1991), 'Career development attributes and occupational values of Asian American and White American college students', Career Development Quarterly, 39: 221-30.

Lynn, R. (1993), 'Sex differences in competitiveness and valuation of money in twenty countries', Journal of Social Psychology, 133: 507-11.

McWhirter, E.H., Hackett, G. and Bandalos, D.L. (1998), 'A causal model of the educational plans and career expectations of Mexican American high school girls', Journal of Counseling Psychology, 45: 166-81.

O'Brien, K.M. (1996), 'The influence of psychological separation and parental attachment on the career development of adolescent women', Journal of Vocational Behavior, 48: 257-74.

Oyserman, D., Coon, H.M. and Kemmelmeier, M. (2002), 'Rethinking individualism and collectivism: evaluation of theoretical assumptions and meta-analyses', Psychological Bulletin, 128: 3-72.

Phillips, S.D., Christopher-Sisk, E. and Gravino, K.L. (2001), 'Making career decisions in a relational context', The Counseling Psychologist, 29: 193-213.

Rothblum, E.D. (1988), 'More on reporting sex differences', American Psychologist, 43: 1095 .

Sagie, A., Elizur, D. and Koslowsky, M. (1996), 'Work values: a theoretical overview and a model of their effects', Journal of Organizational Behavior, 17: 503-14.

Schultheiss, D.E.P. (2003), 'A relational approach to career counseling: theoretical integration and practical application', Journal of Counseling and Development, 81: $301-10$.

Schultheiss, D.E.P., Kress, H.M., Manzi, A.J. and Glasscock, J.M.J. (2001), 'Relational influences in career development: a qualitative inquiry', The Counseling Psychologist, 29: 216-39.

Schultheiss, D.E.P., Palma, T.V., Predragovich, K.S. and Glasscock, M.J. (2002), 'Relational influences on career paths: siblings in context', Journal of Counseling Psychology, 49: 302-10.

Singaravelu, H.D., White, L.J. and Bringaze, T.B. (2005), 'Factors influencing international students' career choice: a comparative study', Journal of Career Development, 32(1): 46-59.

Tang, M., Fouad, N. and Smith, P. (1999), 'Asian American's career choices: a path model to examine factors influencing their career choices', Journal of Vocational Behavior, 54: 142-57.

Triandis, H.C. and Gelfand, M.J. (1998), 'Converging measurement of horizontal and vertical individualism and collectivism', Journal of Personality and Social Psychology, 74: 118-28.

Triandis, H.C., Bontempo, R., Villareal, M.J., Asai, M. and Lucca, N. (1988), 'Individualism and collectivism: cross-cultural perspectives on self-in-group relationships', Journal of Personality and Social Psychology, 54: 323-38.

Triandis, H.C., McCusker, C. and Hui, C.H. (1990), 'Multimethod probes of individualism and collectivism', Journal of Personality and Social Psychology, 59: 1006-20. 